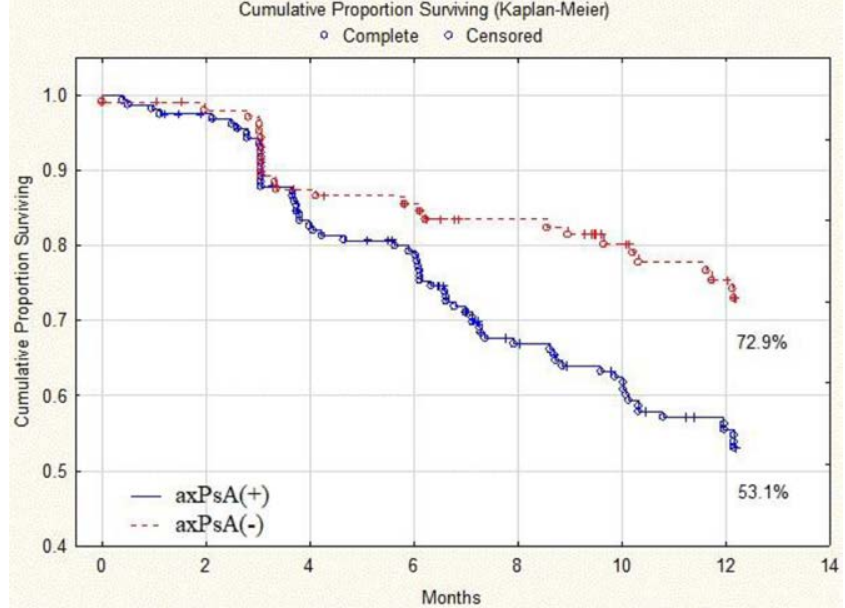

Retention rates of biologic therapy. Differences between $\operatorname{axPsA}(+)$ and $\operatorname{axPsA}(-)$ pts are statistically significant ( $p=0.00265$, log rank test).

Disclosure of Interests: None declared.

DOI: 10.1136/annrheumdis-2021-eular.2007

\section{POS0977 CARDIOVASCULAR AND DISEASE RELATED FEATURES IN AXIAL SPONDYLITIS WITH AND WITHOUT CONCOMITANT PSORIASIS. A MULTICENTER STUDY WITH 882 PATIENTS}

I. González-Mazón ${ }^{1}$, J. Rueda-Gotor ${ }^{1}$, I. Ferraz-Amaro², L. Sanchez-Bilbao', F. Genre ${ }^{3}$, V. Calvo-Río ${ }^{1}$, S. Remuzgo-Martínez ${ }^{3}$, V. Pulito-Cueto ${ }^{3}$, A. Corrales ${ }^{1}$, L. Lera-Gómez ${ }^{3}$, V. Portilla ${ }^{1}$, V. Hernández-Hernández ${ }^{2}$, J. C. QuevedoAbeledo $^{4}$, C. Rodríguez-Lozano ${ }^{4}$, C. López-Medina ${ }^{5}$, M. L. Ladehesa Pineda ${ }^{5}$, S. Castañeda ${ }^{6}$, E. F. Vicente-Rabaneda ${ }^{6}$, C. Fernández-Carballido ${ }^{7}$, M. P. Martínez-Vidal ${ }^{7}$, D. Castro-Corredor ${ }^{8}$, J. Anino-Fernández ${ }^{8}$, D. Peiteado ${ }^{9}$, C. Plasencia ${ }^{9}$, M. L. García Vivar ${ }^{10}$, E. Galindez ${ }^{10}$, E. Montes Pérez ${ }^{11}$, C. Fernández-Díaz ${ }^{1}$, R. Blanco ${ }^{1}$, M. A. González-Gay ${ }^{1,3} .{ }^{1}$ Universitary Hospital Marques de Valdecilla, Rheumatology, Santander, Spain; ${ }^{2}$ Hospital Universitario de Canarias, Rheumatology, Tenerife, Spain; ${ }^{3} I D I V A L$, Epidemiology, Genetics and Atherosclerosis Research Group on Systemic Inflammatory Diseases, Santander, Spain; ${ }^{4}$ Hospital Universitario de Gran Canaria Dr. Negrín, Rheumatology, Las Palmas, Spain; ${ }^{5}$ Reina Sofia Hospital, Rheumatology, Cordoba, Spain; ${ }^{6}$ Hospital de La Princesa, Rheumatology, Madrid, Spain; ${ }^{7}$ Hospital Universitario San Juan de Alicante, Rheumatology, Alicante, Spain; ${ }^{8}$ Hospital General Universitario de Ciudad Real, Rheumatology, Ciudad Real, Spain; ${ }^{9}$ Hospital Universitario La Paz-IdiPaz, Rheumatology, Madrid, Spain; ${ }^{10}$ Hospital Universitario Basurto, Rheumatology, Bllbao, Spain; ${ }^{11}$ Diagnóstico Médico Cantabria, DMC, Santander, Spain

Background: Patients with axial spondyloarthritis (axSpA) may present with concomitant psoriasis (Ps) in approximately $10 \%$ of cases. As with axSpA, Ps is also associated with an accelerated atherosclerosis process ${ }^{1}$. However, it is unknown whether the presence of Ps confers an increased cardiovascular (CV) risk in patients with axSpA

Objectives: To compare factors related to the disease, $\mathrm{CV}$ risk factors, atherosclerotic burden, and CV events in patients with axSpA with and without Ps.

Methods: Cross-sectional analysis of the AtheSpAin cohort, a Spanish multicenter cohort designed for the study of atherosclerosis in axSpA. We compared axSpA patients with and without concomitant psoriasis, focusing mainly on $\mathrm{CV}$ risk characteristics. Background information on $\mathrm{CV}$ risk factors, $\mathrm{CV}$ events, and disease-related factors was reviewed, and data on maximum body index, blood pressure, lipid profile, and disease status at the time of the study were also obtained. Carotid ultrasound (US) was performed in all patients at the time of the study, including measurement of carotid intima-media wall thickness (cIMT) and plaque detection according to the Mannhein consensus criteria.

Results: A set of 882 axSpA patients were included. 786 (89.1\%) of them had no concomitant Ps, which was present in 96 (10.9\%) patients. Although the mean age was similar, male sex was more prevalent in axSpA patients with Ps $(79.1 \%$ Vs $66.5 \%, p=0.01$ ) (Table 1 ).

Furthermore, it was found that axSpA with Ps had a more frequent history of synovitis $(50 \%$ vs $33 \%, p=0.001)$, dactylitis $(13 \%$ vs $6 \%, p=0.011)$ and concomitant inflammatory bowel disease ( $13 \%$ vs $6 \%, p=0.01)$. AxSpA patients with Ps had a non-significant trend towards a higher prevalence of asymmetric sacroiliitis ( $23 \mathrm{vs} 16 \%, p=0.064$ ) and had a lower frequency of positive HLA-B27 status ( $56 \%$ vs $72 \%, p=0.003)$. Regarding the management of the disease, prednisone $(23 \%$ vs $12 \%, p=0.02)$, methotrexate $(30 \%$ vs $15 \%, p=0.000)$ and anti-TNF $\alpha$ therapy $(50 \%$ vs $34 \%, p=0.002)$ were more commonly used in the group with Ps.

Regarding CV risk characteristics, no differences were observed either in the prevalence of traditional CV risk factors (Table 1), nor in the total serum level, HDL and LDL, blood pressure and body mass index at that time of the study. However, axSpA patients with Ps showed a higher prevalence of CV events $(9 \%$ vs $4 \%, p=0.05)$, including ischemic heart disease $(6 \%$ vs $3 \%, p=0.042)$ and ischemic stroke ( $4 \%$ vs $1 \%, p=0.016)$ (Table 1$)$. The subclinical atherogenic burden was also more severe in the group with Ps, with a higher prevalence of carotid plaques $(39 \%$ vs $31 \%, p=0.098)$, and higher values of cIMT $(0.664 \pm$ $0.170 \mathrm{~mm}$ vs $0.642 \pm 0.142 \mathrm{~mm}, p=0.16$ ), although the differences did not reach statistical significance.

Table 1. Main sociodemographic and cardiovascular differences among axSpA patients with and without psoriasis.

\begin{tabular}{lccc}
\hline & $\begin{array}{c}\text { axSpA without } \\
\text { psoriasis (n=786) }\end{array}$ & $\begin{array}{c}\text { axSpA with } \\
\text { psoriasis (n=96) }\end{array}$ & $\mathbf{p}$ \\
\hline Men/Women, $\mathrm{n}$ & $523 / 268$ & $76 / 20$ & $\mathbf{0 . 0 1 0}$ \\
Mean age (years) \pm SD at the time of study & $49 \pm 13$ & $49 \pm 13$ & 0.81 \\
AS/nr-AxSpa & $625 / 166$ & $77 / 19$ & 0.79 \\
History of CV risk factors & & & \\
Current smokers & $267(34)$ & $30(31)$ & 0.60 \\
Obesitty & $174(22)$ & $26(27)$ & 0.29 \\
Dyslipidemia & $262(33)$ & $35(36)$ & 0.48 \\
Hypertension & $211(27)$ & $28(29)$ & 0.57 \\
Diabetes Mellitus & $56(7)$ & $8(8)$ & 0.65 \\
Chronic Kidney Disease & $19(2)$ & $3(3)$ & 0.72 \\
History of cardiovascular events, $\mathbf{n}$ (\%) & $33(4)$ & $9(9)$ & $\mathbf{0 . 0 2 3}$ \\
Ischemic heart disease & $20(3)$ & $6(6)$ & $\mathbf{0 . 0 4 2}$ \\
Congestive heart failure & $2(0)$ & $1(1)$ & 0.29 \\
Ischemic stroke & $6(1)$ & $4(4)$ & $\mathbf{0 . 0 1 6}$ \\
Peripheral artery disease & $6(1)$ & $0(0)$ & 0.99 \\
CV data at the time of study & & & \\
Carotid plaques & $244(31)$ & $38(39)$ & 0.098 \\
IMT mm & $0.642 \pm 0.142$ & $0.664 \pm 0.170$ & 0.16 \\
IMT >= 900 mm & $40(5)$ & $6(6)$ & 0.66 \\
\hline
\end{tabular}

Abbreviations: $\mathrm{AS}=$ ankylosing spondylitis. $\mathrm{AxSpA}=$ axial spondylitis. $\mathrm{CV}=$ cardiovascular. $\mathrm{IMT}$ $=$ intima-media wall thickness. $\mathrm{Nr}$-axSpA $=$ no-radiographic axial spondylitis.

Conclusion: The presence of Ps may confer additional CV risk to axSpA patients and is associated with particular disease related factors.

\section{REFERENCES:}

[1] Fang N, Jiang M, Fan Y. Association Between Psoriasis and Subclinical Atherosclerosis: A Meta-Analysis. Medicine (Baltimore). 2016;95(20):e3576.

Disclosure of Interests: None declared.

DOI: 10.1136/annrheumdis-2021-eular.2025

\section{POS0978 DISEASE CONTROL IN PSORIATIC ARTHRITIS PATIENTS WITH OR WITHOUT AXIAL MANIFESTATIONS IN REAL CLINICAL PRACTICE IN SPAIN: RESULTS FROM THE MIDAS STUDY}

E. De Miguel ${ }^{1}$, J. Gratacos-Masmitja ${ }^{2}$, A. P. Cacheda ${ }^{3}$, J. M. RodríguezHeredia $^{4}$, A. Gallego ${ }^{5}$, E. Beltrán ${ }^{6}$, B. Font Ramos ${ }^{7}$, C. Sastré ${ }^{7}$, C. Sanabra on behalf of MIDAS group. ${ }^{1}$ Hospital Universitario La Paz, Rheumatology Service, Madrid, Spain; ${ }^{2}$ Hospital Universitario Parc Taulí, Rheumatology Service, Sabadell, Spain; ${ }^{3}$ Hospital Universitario Son Llatzer, Rheumatology Service, Palma, Spain; ${ }^{4}$ Hospital Universitario Getafe, RheumatologySservice, Madrid, Spain; ${ }^{5}$ Complejo Hospitalario Universitario Badajoz, Rheumatology Service, Badajoz, Spain; ${ }^{6}$ Hospital del Mar, Rheumatology Service, Barcelona, Spain; ${ }^{7}$ Novartis Farmacéutica, Rheumatology, Barcelona, Spain

Background: MIDAS study assessed the disease activity in psoriatic arthritis (PsA) patients treated in clinical practice in Spain.

Objectives: This sub-analysis compared disease activity between PsA patients with or without axial manifestations.

Methods: MIDAS is an observational, non-interventional, cross-sectional, multicenter study conducted in Spain. Patients included were $\geq 18$ years old with $\geq 6$ months since diagnosis, were classified by CASPAR criteria and had initiated treatment $\geq 3$ months. Disease activity was measured by Disease Activity in Psoriatic Arthritis (DAPSA) and Minimal Disease Activity (MDA). Axial involvement was defined according to the presence of inflammatory back pain assessed by rheumatologist.

Results: 312 evaluable PsA patients were included in this analysis, $12.2 \%$ of which presented with axial involvement. PsA patients with axial manifestations reported longer time from onset of symptoms to diagnosis and disease duration, higher presence of concomitant diseases, $H L A-B^{\star} 27+$ status, C-reactive protein 